familiar torms. Swing, slide and spin provide a protty example of alliteration but become confusing in practice, and the use of the term "myone" for motor unit has little advantage. An attempt has been made to simplify the mathematics of the subject, but this is marred in more than one place by inaccuracies in the text and the use of diagrams which, in spite of the authors' exhortation, do not clearly indicate all the forces involved in a mechanical problem. Physiology, apart from a possibly misleading reference to the lengthening of a muscle fibre "by simple relaxation", is intentionally ignored and as a result the impression is gained that the design of musclos is determined only by their geometry.

The remainder of the book is a useful summary of contributions made to the study of muscle action in vivo which have not yet been incorporated into standard texts. Many of these contributions have been made by the authors themselves and adcquato reference is given to others working in this field. Old and new theories are discussed in the light of electromyographic findings and admission is made where these have yet to provide a complete answer.

In a final short section on "applications and problems", acknowledgment of the variability of human nature and physique must provide little to convince many of the readers at whom this book is aimed that their labour has been worthwhile. Reference to the book in the teaching of human morphology will, however, help in the selection of detail of practical value and give rhyme and reason to the variety of musculoskeletal design in man. E. C. B. HALL-CRAGGS

\section{CRUSTACEAN TAXONOMY}

Treatise on Invertebrate Paleontology

Part R: Arthropoda 4. Directed and edited by Raymond C. Moore. (Prepared under Sponsorship of the Geological Society of America.) Vol. 1: Pp. xxxvi+398. Vol. 2: Pp. ii + 399-651. (Geological Society of America: Boulder, Colorado; University of Kansas: Lawrence, 1969.) \$19 the two volumes.

THEse long-awaited and most wolcome volumes of the Treatise on Invertebrate Paleonlology are noteworthy for the large panel of distinguished palacontologists and neontologists who have contributed to them. 'The panel is composed of the seventeen authors and a large number of other specialists who have advised or assisted. Tho present two volumes are devoted to Crustacea (cxcept Ostracoda, which are doalt with in part $Q$ which has already been published) and Myriapoda; a third volume on the Hexapoda is in course of preparation.

As in the other parts of the treatise the essence of the volumes is a presentation of tho current views of the individual authors regarding the classification of the Crustacea and Myriapoda, with a conciso diagnosis for each taxon down to generic level. For this reason alone they become definitive works and an essential source of reference for those working on crustacean taxonomy. But, more than this, a large part of these particular volumes is devoted to accounts of the morphology, ontogeny, mode of life and stratigraphy of the classes, which with good bibliographins make them invaluable source books for students of zoology as well as palaeontology.

Although they form part of a palacontological treatiso, these volumes acknowledgo the fact that thore has been a major differenee of views between palaeontologists and neontologists rogarding the evolution of the Crustacea, and each camp has its own version of a natural classification. Thus it is of particular interest that two of the most stimulating contributions to the volumes, both by Sidnie Manton, are devoted to an "Introduction to Classification of Arthropoda" and to the "Evolution and Affinities of Onychophora, Myriapoda, Hexapoda and Crustacea".
Similarly, the valuable introduction to the Decapoda by M. F. Glaessner includes a review of their phylogeny.

As might be expected in a compilation of this kind, there are points on which specialists in the various fields might wish to differ with the contributors. This does not, however, detract from the overall value of an important work in a hitherto much neglected field of palaeontological studies. All of the contributors, and in particular the director and editor R. C. Moore (who has in this as in other parts of the treatise taken under his wing the inevitable "orphan" groups which no one wants to own, plus a lengthy "General Features of Crustacea" scction in conjunction with L. McCormick), are to be congratulated on the results of their labours.

Palaeontologists, already familiar with the format, excellent standard of production and ample illustration of other parts of the treatise, will need no other comment, than that these volumes are among the best so far published (though, it must be added, they are also among the most expensive). Zoologists who will be less familiar with the treatise are urged not to neglect what at first sight of the title might seem to be, for them, barren territory.

H. W. BALI

\section{CIRCULATION STUDIES}

\section{General Climatology, 2}

Edited by H. Flohn. (World Survey of Climatology, Vol. 2.) Pp. xii + 266. (Elsevier: Amsterdam, London and New York, 1969.) 225s.

This is one of a series of fifteen volumes, the first three of which, with the title General Climatology, are to consist of chapters written by well known specialists. This volume, containing five of these essays, is the first of the three to bo published.

In the opening chapter on mechanisms of the general circulation of the troposphere, $H$. Riehl begins by giving $a$ brief review of the classical model leading to an account of model experiments. He then discusses critically analytical solutions of the high-tropospheric wind field, the mechanism of momentum exchange and of heat and moisture exchange, the kinetic energy generation and maintenance and the general circulation in wave coordinates, concluding with tho remark that "understanding of the general circulation will be advanced by choosing the coordinate system most appropriate to the type of eirculation studied".

F. L. Deacon, under the title "Physical Processes near the Surface of the Earth", surveys work on microclimates over level uniform terrain and extensive water surfaces. Ho examines in detail the whole range of surface-atmosphere interactions and includes accounts of the different kinds of fog and of turbulent diffusion of air-borne material.

R. Geiger extends these chiefly microclimatic studies to sloping terrain in a chapter on topoclimates, topoclimatology being defined as the subdivision of general climatology dealing with relationships between land forms and local climates. Beginning with the astronomical theory and examining the effects of screening of the horizon and of clouds, he describes the construction of radiation maps and then the climato of slopes generally. Succeding sections deal with the climate of valleys, microclimates in mountainous regions, including the climate of eaves, and the difficulties of the mapping of topoclimates. He forecasts that "the use of topoclimatic maps will become quite usual in the foreseeable future in the same way as we now use geological maps showing the subsoil or tho ground surface for planning purposes".

The editor of this volume, H. Flohn, contributes a chapter on local wind systems, beginning with accounts of examples, followed by the theory, of simple thermally driven cireulations, land and sea breezes. Cases of more 